\title{
Recurso de apelación en el proceso verbal inmediato. Autoridad competente para resolverlo: riesgo de impedimento o recusación*
}

\author{
[Artículos]
}

\author{
Marco Antonio Moreno Ramírez ${ }^{* *}$ \\ Fernando Antonio Moreno González ${ }^{* * *}$ \\ Lina Stefanía Arévalo Sanabria ${ }^{* * *}$
}

Recibido: 23 de marzo de 2021

Aceptado: 6 de mayo de 2021

\begin{abstract}
* Este artículo es producto de la investigación: "Recurso de apelación en el proceso verbal inmediato. Autoridad competente para resolverlo: riesgo de impedimento o recusación", desarrollado en la Facultad de Derecho de la Universidad Libre, Bogotá, Colombia.

** Coronel (R) de la Policía Nacional, administrador policial, abogado, especialista en Derecho de Policía y Docencia Universitaria. Docente de la cátedra de Derecho de Policía en la Escuela de Suboficiales y Nivel Ejecutivo "Gonzalo Jiménez de Quesada" de la Policía Nacional de Colombia. Correo electrónico:

marcoantoniomorenoramirez@hotmail.com; ORCID: https://orcid.org/0000-0003$\underline{1698-7068}$

${ }_{* * *}$ Administrador policial, abogado, especialista en Derecho Administrativo, Tributario y Docencia Universitaria, magíster en Derecho Administrativo y Derecho Penal y doctorando en Derecho Laboral. Docente de la Universidad Libre, Universidad Gran Colombia y Colegio Mayor de Cundinamarca. Asesor de la Secretaría General del Instituto Nacional de Medicina Legal y Ciencias Forenses. Correo electrónico: fernandoantoniomorenogonzalez@gmail.com; ORCID: https://orcid.org/0000-00032785-0171

${ }_{* * *}$ Abogada, especialista en Derecho Administrativo, magíster en Derecho Administrativo y estudiante de la Especialización en Docencia Universitaria. Docente de la cátedra de Derecho de Policía en la Escuela de Suboficiales y Nivel Ejecutivo "Gonzalo Jiménez de Quesada" de la Policía Nacional de Colombia. Abogada de la Subdirección de Gestión Corporativa de la Fundación Gilberto Álzate Avendaño. Correo electrónico: arevalosanabria.I@hotmail.com; ORCID: https://orcid.org/0000-00026748-1553
\end{abstract}


Citar como:

Moreno Ramírez, M. A., Moreno González, F. A. y Arévalo Sanabria, L. S. (2021). Recurso de apelación en el proceso verbal inmediato. Autoridad competente para resolverlo: riesgo de impedimento o recusación. Revista IUSTA, (55). https://doi.org/10.15332/25005286.6857

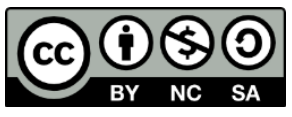

\section{Resumen}

Este artículo analiza un error, abiertamente ilegal, en el que incurren autoridades de policía, académicos, eruditos y litigantes, al aceptar, tácita o expresamente, que los inspectores de policía y corregidores son competentes para resolver el recurso de apelación contra las medidas correctivas impuestas por miembros uniformados de la Policía Nacional, designados como comandantes de estación, subestación o Centros de Atención Inmediata. El análisis evidencia que esta competencia no es del inspector de policía ni del corregidor, de conformidad con los preceptos constitucionales, la jurisprudencia de la Corte Constitucional y del Consejo de Estado y la Ley 1801 de 2016. Además, se muestra que si el recurso de apelación contra decisiones de policía tomadas por los anteriores comandantes es resuelto por el inspector o corregidor, estos podrían ser objeto de investigación penal y disciplinaria, o podría derivar en la declaración de nulidad del acto por parte de la Jurisdicción de lo Contencioso Administrativo.

Palabras clave: apelación, comandante, corregidor, inspector, modificar, revocar. 


\section{Appeal in the immediate oral process. Competent authority to resolve it: risk of impediment or recusal}

\section{Abstract}

This article analyzes an error, clearly illegal, that is being committed by police authorities, academics, scholars and litigants, in this area of Law, by accepting, tacitly or expressly, that police inspectors and "corregidores" are competent to resolve the appeal against corrective measures imposed by uniformed members of the National Police, designated as commanders of station, substations or Immediate Attention Centers. The analysis evidences that this authority does not belong to the police inspector or corregidor, in accordance with the constitutional precepts, the jurisprudence of the Constitutional Court and the Council of State and Law 1801 of 2016. Furthermore, it is shown that if the appeal against police decisions made by the former commanders is resolved by the inspector or corregidor, they could also be the subject to criminal and disciplinary investigation, or it could result in the declaration of nullity of the act by the Contentious Administrative Jurisdiction.

Keywords: appeal, commander, corregidor, inspector, modify, revoke.

\section{Recurso de apelação no processo verbal imediato. Autoridade competente para resolvê-lo: risco de impedimento ou recusa}

\section{Resumo}

Neste artigo, analisa-se um erro, abertamente ilegal, no qual incorrem autoridades de polícia, acadêmicos, eruditos e litigantes, ao aceitar, tácita ou expressamente, que os inspectores de polícia e corregedores são competentes para resolver o recurso de apelação contra as medidas corretivas impostas por membros uniformados da Polícia Nacional, 
designados como comandantes de estação, subestação ou Centros de Atenção Imediata. A análise evidencia que essa competência não é do inspector de polícia nem do corregedor, de acordo com os princípios constitucionais, com a jurisprudência da Corte Constitucional e do Conselho de Estado e da Lei 1.801 de 2016. Além disso, é mostrado que, se o recurso de apelação contra decisões de polícia tomadas por anteriores comandantes é resolvido pelo inspetor ou pelo corregedor, eles poderiam ser objeto de investigação penal e disciplinar ou se poderia derivar na declaração de nulidade do ato por parte da jurisdição do contencioso administrativo.

Palavras-chave: apelação, comandante, corregedor, inspector, modificar, revocar.

\section{Introducción}

En Colombia impera el Estado social de derecho, en el cual se propende por las garantías de los derechos de los administrados. Uno de los derechos fundamentales consiste en garantizar el debido proceso, en este se halla inmerso, entre otros, el derecho a la defensa y contradicción, estipulado en el Artículo 29 de la Constitución Política (Borbón, 2019), del cual se desencadena el principio de la doble instancia que, básicamente, se encarna en el recurso de apelación. Este último permite que las decisiones de fondo tomadas por las autoridades en primera instancia puedan ser impugnadas y, luego, analizadas y revisadas por el superior jerárquico o funcional, en aras de una decisión justa enmarcada en el principio de legalidad.

En el área del derecho de policía, específicamente, en el contexto de la Ley 1801 de 2016, una vez proferido el acto de policía, como culminación del proceso verbal inmediato, es viable interponer por el presunto infractor el 
recurso de apelación ${ }^{1}$; no obstante, se encuentran vacíos legislativos que parecen dejar al libre arbitrio la competencia para resolverlos, pues parece presentarse una indefinición acerca de qué autoridad, en concreto, debe decidir este recurso.

En este artículo se pretende establecer cuáles son los fundamentos jurídicos en los cuales se soporta la tesis acerca de la falta de competencia por parte de los inspectores de policía y corregidores para resolver el recurso de apelación, cuando este se interpone por una medida correctiva impuesta por un miembro uniformado de la Policía Nacional, a quien se ha designado como comandante de estación, subestación o Centro de Atención Inmediata (CAI).

Según la legislación vigente, el recurso de apelación es parte fundamental del debido proceso verbal inmediato (Ley 1801 de 2016, art. 222, Colom.), de manera que los miembros de la Policía Nacional deben observar este proceso con competencia para imponer medidas correctivas. La Ley 1801 de 2016 divide a este personal uniformado en dos grandes grupos: por una parte, aquel sin cualificación (Ley 1801 de 2016, art. 210, Colom.) y, por otra, los uniformados que se desempeñan como comandantes de estación, subestación o CAI (Ley 1801 de 2016, art. 209, Colom.). Por ende, en la Policía Nacional no todo el personal uniformado está investido de las mismas competencias, en relación con la imposición de medidas correctivas. Así, unas son atribuidas a aquellos que no ostentan la calidad

\footnotetext{
${ }^{1}$ Se resalta que el recurso de apelación es un instrumento procesal consagrado en la Ley 1801 de 2016, en el marco del proceso verbal inmediato, para ejercer el derecho a la defensa, contradicción y doble instancia, con el propósito de promover, por parte del presunto perturbador de la convivencia, una oposición jurídica o de facto contra las decisiones de fondo de competencia del personal uniformado de la Policía Nacional, los comandantes de estación y subestación, y los comandantes de Centros de Atención Inmediata (CAI). Este recurso tiene como objeto que el superior funcional o jerárquico aclare, adicione, modifique, revoque o confirme una decisión tomada en primera instancia.
} 
de comandantes y otras las otorgadas a quienes sí son comandantes de estación, subestación o $\mathrm{CAI}^{2}$.

\section{La Constitución frente a las competencias atribuidas a las autoridades}

Uno de los pilares sobre los cuales descansa el Estado de derecho es el ejercicio reglado de las competencias, esto significa que toda autoridad solo puede hacer lo que la Constitución y la ley, expresamente, le permitan (Torregrosa y Villalba, 2020). Por consiguiente, si una autoridad, explícitamente, no está facultada para hacer algo, no deberá hacerlo, pues estaría desbordando sus atribuciones; esta regla, relacionada con las potestades o competencias atribuidas a las autoridades, emana directamente de la Constitución Política, que establece: "Ninguna autoridad del Estado podrá ejercer funciones distintas a las que le atribuye la Constitución y la ley" (C.P., 1991, art. 121, Colom.). Por lo anterior, al funcionario le está vedado arrogarse funciones que no se le han otorgado, pues de lo contrario incurriría en un abuso, atropello, exceso o extralimitación, cuyas consecuencias pueden ser de índole disciplinario y penal.

\footnotetext{
${ }^{2}$ Es conveniente advertir que el legislador no le confiere la competencia para imponer determinadas medidas correctivas a cualquier nivel o clase de comandante; esta facultad se asigna solo a quienes ostentan la categoría de comandantes de estación, de subestación o CAI de la Policía Nacional. De manera que si un comandante de distrito, un comandante operativo o un comandante de departamento de policía impone una medida correctiva, para efectos de lo preceptuado en el Código Nacional de Seguridad y Convivencia Ciudadana, se le considera como personal uniformado, mas no como comandantes. La razón es que las potestades especiales para imponer determinadas medidas correctivas únicamente fueron concebidas por el legislador para quienes, normalmente, están en permanente trato, familiaridad o contacto con la comunidad, es decir, quienes se desempeñan como comandantes de estación, subestación o CAI.
} 
De las normas constitucionales ${ }^{3}$ claramente se colige que a los servidores públicos les está vedado asumir competencias o potestades por analogía, inferencia, suposición, proximidad, afinidad o deducción (Mendieta, Goyte y Oviedo, 2020). Las competencias son precisas y expresas, por lo tanto, si no están claramente plasmadas en la norma, no se deben asumir, ni siquiera por motivos nobles o altruistas, en aras de un presunto mejor servicio, o con el argumento de que el asunto le ha llegado a su conocimiento porque le fue remitido.

\section{Jurisprudencia de la Corte Constitucional en relación con las competencias atribuidas a las autoridades}

La jurisprudencia de la Corte Constitucional, tanto en acciones de constitucionalidad como de tutela, insistentemente, ha advertido acerca de los límites o barreras a las que están sometidos los servidores públicos, en la toma de sus decisiones, es decir, en ejercicio de sus competencias.

\footnotetext{
${ }^{3}$ Otra norma constitucional relacionada es la siguiente: "Los particulares solo son responsables ante las autoridades por infringir la Constitución y la ley. Los servidores públicos lo son, por la misma causa, y por omisión o extralimitación en el ejercicio de sus funciones" (C.P., 1991, art. 6, Colom.). En esta norma claramente se expresan las consecuencias jurídicas que podrían recaer sobre los servidores públicos que incurran en extralimitación en el ejercicio de sus funciones; así, cuando la propia Constitución establece que el funcionario público que se extralimite en el ejercicio de sus funciones será responsable, diáfanamente, está advirtiendo una consecuencia jurídica para dicho funcionario. En otro artículo de la Constitución Política, se insiste en que las funciones que ejercen los servidores públicos únicamente son las detalladas en la Constitución o el reglamento: "No habrá empleo público que no tenga funciones detalladas en ley o reglamento y para proveer los de carácter remunerado se requiere que estén contemplados en la respectiva planta y previstos sus emolumentos en el presupuesto correspondiente" (C.P., 1991, art. 122, Colom.). Esta norma reitera que las funciones, esto es, las competencias o facultades otorgadas a los funcionarios públicos, deben estar claramente detalladas en la ley. Asimismo, insiste en una exigencia: que la potestad esté precisada, lo que indica que la función debe ser específica, puntual, prolija y rigurosa; por consiguiente, no puede dar lugar a dudas, incertidumbres, anfibologías, confusiones, manipulaciones o interpretaciones distorsionadas. Así, bajo ningún pretexto, un funcionario público puede arrogarse funciones no detalladas en la ley, menos aún cobijado en conjeturas o elucubraciones.
}

Revista IUSTA

ISSN: 1900-0448 | e-ISSN: 2500-5286 | DOI: https://doi.org/10.15332/25005286

N. 055 | julio-diciembre del 2021 
A continuación, se retoman aspectos puntuales acerca del ejercicio reglado de las competencias en las siguientes sentencias:

\section{Sentencia C-337/1993}

En relación con la cláusula general de competencia, de manera tajante, la Corte Constitucional manifiesta:

Por otra parte, para la Corte no es de recibo el argumento de que el Gobierno puede perfectamente atender una serie de asuntos relacionados con el tema en cuestión, por cuanto la Constitución no prohíbe, expresamente, dicha actuación [...]. Los servidores públicos tan solo pueden realizar los actos previstos por la Constitución, las leyes o los reglamentos, y no pueden, bajo ningún pretexto, improvisar funciones ajenas a su competencia. (C.C., Sentencia C-337/93, Colom.)

\section{Sentencia C-725/2000}

Sobre las competencias regladas, esta corporación expresó que:

Como se sabe, en un Estado de derecho la actividad que en ejercicio de sus funciones se cumple por los servidores públicos, no puede ser arbitraria, ni tampoco dejarse al capricho o las concepciones personales que sobre el Estado y la función pública se tengan, sino que se trata de una actividad reglada, esto es, que ha de desempeñarse conforme a las normas que para el efecto establezcan la Constitución, la ley o el reglamento.

Como tal responsabilidad (la de los servidores públicos) puede ser de índole civil, penal o disciplinaria, ha de recordarse ahora que las modalidades de esta son de naturaleza jurídica diferente, son independientes la una de la otra y, en virtud de ello, un mismo hecho puede generar distintas consecuencias respecto de cada uno de los tipos 
de responsabilidad aquí mencionados. (C.C., Sentencia C-725/oo, Colom.)

\section{Sentencia C-319/2007}

Esta Sentencia constituye un derrotero para que los funcionarios públicos se ubiquen en el contexto de sus facultades. La jurisprudencia de la Corte Constitucional insiste en que las competencias de los funcionarios públicos no pueden inferirse o invocarse por analogía:

[...] en un Estado de derecho no pueden existir competencias implícitas, por analogía o por extensión, porque ello permitiría que la autoridad pública se atribuya competencias según su voluntad y capricho, trazándose los límites de su propia actividad, invadiendo la órbita de actuación de las otras autoridades, abusando del poder y cercenando los derechos y libertades públicas. (C.C., Sentencia C-319/o7, Colom.)

\section{Sentencia C-428/2019}

En algunos apartados de esta Sentencia se ratifica la línea jurisprudencial acerca de la taxatividad y precisión en la norma jurídica para que un funcionario público esté legalmente habilitado para ejercer una función o, lo que es lo mismo, hallarse expresamente con competencia para desplegar determinada potestad:

De este modo (con el principio de legalidad), (i) se protege la dignidad humana, al reconocer la capacidad de las personas para ajustar su conducta a las prescripciones de las normas; (ii) se evita la arbitrariedad, tan ajena a la noción de Estado de derecho; (iii) se asegura la igualdad en la aplicación de las normas y, por esta vía, se refuerza la legitimidad del Estado; y (iv) se fortalece la idea de que en un Estado de derecho el principio general es la libertad. (C.C., Sentencia C-428/19, Colom.) 


\section{Corte Constitucional: autos 016/2008 y 059/2009}

La importancia de estos dos autos radica en que se trata de una decisión, no de un magistrado, sino de todos los magistrados de la Corte, es decir, de la Sala Plena. Además, en ambos autos se resuelve un problema que, de ninguna manera, es de competencia de esta Corte, por disposición expresa de la Constitución Política (1991)4.

Ante este presunto abuso de poder surge, entonces, el salvamento de voto del magistrado Jaime Araujo Rentería, considerado como una pieza jurídica magistral, en la cual se le recuerda a la Corte Constitucional que incluso ella tiene límites plasmados en la propia Constitución. El siguiente texto contiene apartes del salvamento de voto:

[...] La Corte Constitucional, por muy alta que sea su misión es un órgano aplicador de la Constitución y no un órgano creador de esta, de manera tal que el vacío sobre la falta de competencia para dirimir conflictos de competencia en materia de tutela no puede llenarlo la propia Corte Constitucional, sino que debe ser establecido por el propio constituyente o, en su defecto, por el legislador. [...] La falta de norma expresa no puede suplirse con la falacia de que por ser la Corte Constitucional el juez máximo de la jurisdicción constitucional tiene, implícitamente, esa competencia. [...] Colombia es un Estado de derecho y, por tanto, la competencia es un asunto del constituyente o del legislador; que los funcionarios públicos al tenor de lo dispuesto en el artículo 6 del Estatuto Supremo, solamente pueden hacer aquello para lo cual están

\footnotetext{
${ }^{4}$ En las dos oportunidades, la Corte Constitucional asume el problema de resolver un conflicto de competencia, asunto completamente ajeno a sus funciones, ya que por expresa disposición de la Constitución, la autoridad competente para abocar la resolución del conflicto de competencias entre jurisdicciones, en ese entonces, era el Consejo Superior de la Judicatura, de conformidad con lo preceptuado por la Carta, así: "corresponde al Consejo Superior de la Judicatura, o a los Consejos Seccionales, según el caso y de acuerdo con la ley, [...] 6. dirimir los conflictos de competencia que ocurran entre las distintas jurisdicciones" (C.P., 1991, art. 256, núm. 6, derogado, Colom.).
} 
expresamente facultados por el ordenamiento; que no existen facultades implícitas [...] y que la competencia es un presupuesto de validez de los actos que se profieren, de manera que si una autoridad pública expide un acto sin tener competencia para hacerlo, este carece de validez, [...] es nulo. (C.C., Auto 059/09, 2009, Colom.)

Este salvamento de voto ha sido crucial para pensar en modificar la Constitución Política, entre otros asuntos, en relación con la autoridad competente para resolver los conflictos de competencia entre jurisdicciones. Esta modificación se logró y, a partir del 1 de julio de 2015, el Consejo Superior de la Judicatura perdió esta potestad, que había ostentado desde la promulgación de la Constitución de 1991, con fundamento en su Artículo 256, numeral 6 -que fue derogado- (Acto Legislativo 02 de 2015, art. 17)5.

\section{Sentencia T-385/2019}

En esta Sentencia, la Corte Constitucional se pronuncia de manera contundente sobre la violación del principio de legalidad, traducido en la falta de competencia de las autoridades de policía, en un caso concreto, que se resume a continuación.

El 25 de noviembre de 2018, un miembro uniformado de la Policía Nacional, en Medellín, solicitó la cédula de ciudadanía a un ciudadano que no la portaba, por esta razón, el policía le impuso un comparendo, multa tipo 4, equivalente a 32 salarios mínimos diarios, por transgresión del Artículo 35 del Código Nacional de Policía y Convivencia, por "impedir,

\footnotetext{
${ }^{5}$ Desde entonces, constitucionalmente, esta competencia fue otorgada a la Corte Constitucional, en forma expresa: "agréguese un numeral 12 y modifíquese el 11 del artículo 241 de la Constitución Política, los cuales quedarán así: 11. Dirimir los conflictos de competencia que ocurran entre las distintas jurisdicciones. 12. Darse su propio reglamento" (Acto Legislativo 02 de 2015, art. 14).
} 
dificultar, obstaculizar o resistirse a procedimiento de identificación o individualización, por parte de las autoridades de policía” (Ley 1801 de 2016, art. 35, núm. 3, Colom.). En sede de apelación, la multa fue ratificada por el Inspector 10D de Policía Urbana de Medellín el 28 de noviembre de 2018, y el ciudadano, en ese entonces, debía cancelar al erario público de esa ciudad la suma de $\$ 833325$.

El ciudadano consideró que la multa no se ajustaba al principio de legalidad, por lo tanto, acudió en defensa de sus derechos mediante una acción de tutela, que fue avocada el 18 de diciembre de 2018 por el Juez Primero Municipal de Medellín; el 31 de diciembre de 2018 el Juez negó la acción de tutela por considerarla improcedente. Esta decisión no fue impugnada, no obstante, ante la inminente arbitrariedad, por violación al principio de legalidad debido a la falta de competencia, tanto del miembro de la Policía Nacional como del Inspector 10D de Policía Urbana de Medellín, esta tutela fue seleccionada para revisión por la Corte Constitucional, el 30 de abril de 2019.

Después de un análisis exhaustivo, la Corte concluyó que no existe, ni en la Ley 1801 de 2016 ni en otras normas del ordenamiento jurídico colombiano, una disposición que faculte o le confiera competencia a un miembro uniformado policial para expedir orden de comparendo porque un ciudadano no porte su cédula de ciudadanía. Tampoco existe, en el ordenamiento jurídico colombiano, una disposición que faculte o le confiera competencia a los inspectores o corregidores para que, en sede de apelación, se ratifique la decisión de un uniformado, completamente alejada de la realidad fáctica y jurídica.

Uno de resultados finales de esta sentencia de tutela es que, en contra de dos miembros uniformados de la Policía Nacional y en contra del 
Inspector 10D de Policía Urbana de Medellín, se compulsaron copias, así: a la Policía Nacional, para que se procediera a investigar disciplinariamente a los dos uniformados de la institución policial; a la Procuraduría General de la Nación para que se adelantara la correspondiente investigación disciplinaria contra del Inspector 10D de Policía Urbana de Medellín; y a la Fiscalía General de la Nación, para que a los anteriores tres servidores públicos se les adelantara el correspondiente proceso penal (C.C., Sentencia T-385/19, Colom.).

\section{Jurisprudencia del Consejo de Estado en relación con las competencias atribuidas a las autoridades administrativas}

\section{Sentencia del Consejo de Estado, del 19 de septiembre de 2016} (Expediente 47693)

En esta Sentencia, el Consejo de Estado realiza una pormenorizada exposición sobre una consecuencia que, de manera ineludible, debe ocurrirle a un acto administrativo emitido sin competencia para promulgarlo: la declaración de nulidad. No obstante, para mayor ilustración, es procedente transcribir algunas consideraciones jurisprudenciales específicas sobre la falta de competencia, que anulan el acto administrativo:

4.1.- El de falta de competencia es uno de aquellos vicios invalidantes de los actos administrativos [...]. Así lo dispone el inciso segundo del artículo 137 del Código de Procedimiento Administrativo y de lo Contencioso Administrativo al preceptuar que se declarará la nulidad de los actos "cuando hayan sido expedidos con infracción de las normas en que debería fundarse, o sin competencia”. [...] una perspectiva analítica del vicio de incompetencia en el acto administrativo permite, a la vez, distinguir entre incompetencia en razón a la materia, al territorio, tiempo, por el grado de horizontalidad o verticalidad, por usurpación de 
poder o por la presencia de funcionarios de hecho. [...] baste indicar que el grado de jerarquía existente entre funcionarios administrativos o entre organismos de la Administración Pública, no los faculta para variar la competencia establecida por normas superiores. El superior jerárquico, [...] no podrá asumir las que correspondan a su inferior, mucho menos el inferior atribuirse las de su superior. (C.E., Expediente 47693/16, Colom.)

\section{Síntesis de la jurisprudencia de la Corte Constitucional y del Consejo de Estado, en relación con las competencias atribuidas a las autoridades administrativas}

Como resumen de lo expresado y reiterado, tanto por la Corte Constitucional como por el Consejo de Estado, en relación con la atribución de competencias a los servidores del Estado, se puede concretar que, una vez más, se anuncian o se avizoran las potenciales consecuencias jurídicas, de las cuales puede ser objeto el servidor público que ejerza potestades que expresamente no le estén otorgadas en la ley. Se manifiesta que podrá ser objeto de una responsabilidad civil, penal y disciplinaria, además, se recuerda que en un mismo hecho puede suscitar diversas consecuencias, en relación con las clases de responsabilidad.

Por otro lado, la jurisprudencia mencionada insiste en que el ejercicio reglado de las competencias está estrechamente vinculado con el ejercicio del poder; si una norma jurídica confiere competencias a un funcionario público, lo está invistiendo de poder para hacer, decidir o proceder; incluso, en muchos casos, lo faculta para restringir o privar derechos de las personas.

La exigencia de que un servidor público realice solo lo que el ordenamiento jurídico prescribe radica en que esa facultad le confiere poder, y las personas con poder tienden a abusar de este. Por eso es que las facultades 
deben establecerse anticipadamente en la ley, en forma expresa, clara y precisa; si, en relación con competencias, existe vaguedad, indeterminación o duda y, no obstante, el funcionario actúa, se dará lugar a la arbitrariedad, al abuso y a la inseguridad jurídica. En suma, el ejercicio reglado de las competencias también es un principio rector que subyace al principio de legalidad, e implica que los funcionarios públicos solamente pueden hacer lo que previamente ha sido prescrito, detallado y definido por la norma jurídica, en forma expresa, clara y precisa (Vargas, 2018).

Por último, el Consejo de Estado enfatiza y advierte en su jurisprudencia que la falta de competencia es causal, por sí sola, de la ilegalidad del acto; igualmente, considera y advierte que una de las maneras de violar el principio de legalidad es asumir competencias que expresamente no han sido otorgadas; además, hace referencia a la usurpación de competencias, cuando un servidor público se arroga facultades que, por ley, han sido conferidas a otro funcionario de mayor o menor jerarquía (C.E., Expediente 47693/16, Colom.).

\section{Recurso de apelación en el proceso verbal inmediato. Competencia e incompetencia del inspector de policía para resolverlo}

Después de más de cinco años de promulgada la Ley 1801 de 2016, que estableció el Código Nacional de Seguridad y Convivencia Ciudadana, algunos inspectores de policía y corregidores continúan asumiendo la competencia para resolver el recurso de apelación interpuesto contra las medidas correctivas impuestas por los comandantes de estación, subestación o CAI de la Policía Nacional. Además, se escuchan voces de eruditos académicos y jurisconsultos del derecho de policía que, sin suficiente reflexión jurídica, pregonan que, contra los actos administrativos de policía emitidos por todos los miembros uniformados 
de la Policía Nacional, procede el recurso de apelación, cuya resolución estará a cargo de un inspector de policía.

De conformidad con la legislación actual, es parcialmente verdadero afirmar que contra los actos administrativos de policía emitidos por los miembros uniformados de la Policía Nacional procede el recurso de apelación, cuya resolución estará a cargo de un inspector de policía. Pero, como todo lo parcialmente verdadero también es relativamente falso, pues por imperio de la ley existen determinados uniformados de la Policía Nacional que, al imponer medidas correctivas hacen que el respectivo recurso de apelación no sea de competencia del mencionado inspector.

\section{Competencia de los inspectores de policía y corregidores, según calidad de los uniformados}

Por mandato legal, no todos los miembros uniformados de la Policía Nacional se encuentran en el mismo nivel o categoría para efectos de la imposición de medidas correctivas; por ello, no todos los uniformados tienen al inspector de policía o al corregidor como autoridad competente para la resolución del recurso de apelación, en el evento en que este se interponga.

La Ley 1801 de 2016 establece las competencias atribuidas al personal uniformado de la Policía Nacional que no ostenta la calidad de comandante. Solo para esta clase de servidores, cuando se impongan medidas correctivas y estas hayan sido apeladas, la autoridad competente para resolver la apelación es el inspector de policía o el corregidor, según la ley cuando preceptúa: "Contra las medidas previstas en este artículo se 
concede el recurso de apelación en el efecto devolutivo que resolverá un inspector de policía” (Ley 1801 de 2016, art. 210, par. 2, Colom.) 6 .

Por imperio de la normatividad vigente (Ley 1801 de 2016, art. 209 y 210, Colom.), para efectos de emisión de actos administrativos, los miembros uniformados de la Policía Nacional se dividen en dos grupos bien definidos: por un lado, se encuentra el personal uniformado, que funge como comandantes de estación, subestación y CAI (Ley 1801 de 2016, art. 209, Colom.) y, por otro, el resto de uniformados que no ostentan esta responsabilidad (Ley 1801 de 2016, art. 210, Colom.).

En la legislación vigente no existe una norma expresa, clara y precisa, que manifieste cuál es la autoridad competente para resolver el recurso de apelación cuando la medida correctiva es impuesta por uno de los comandantes relacionados en el Artículo 209 de la Ley 1801 de 2016. Pero este aparente vacío jurídico de ninguna manera puede ser cubierto por un inspector de policía o un corregidor, pues las competencias no se pueden acometer por analogía o por inferencia, en aplicación de la jurisprudencia constitucional, en la cual se manifiesta que al funcionario público lo que no le está expresamente atribuido, le está prohibido (C.C., Auto 016/o8, Colom.).

\footnotetext{
${ }^{6}$ La expresión empleada por el legislador, relacionada con las palabras "este artículo", significa un límite, mojón o hito expreso impuesto al inspector de policía o corregidor. La expresión "este artículo" indica, clara y tajantemente, que un inspector de policía o un corregidor no están habilitados para resolver el recurso de apelación sobre las medidas correctivas impuestas por otros miembros uniformados cualificados como comandantes, previstas en otras normas jurídicas de la ley mencionada; por lo tanto, un inspector de policía o un corregidor podrá abocar el recurso de apelación, únicamente en relación con las medidas impuestas por los servidores públicos aludidos en el artículo 210 de la Ley 1801 . Si un inspector de policía o un corregidor asume la competencia para resolver el recurso de apelación contra un uniformado de la Policía Nacional que ostenta el cargo o responsabilidad de comandante de estación, subestación o CAI, se presenta una usurpación de funciones o potestades, pues ninguna norma los ha facultado para ello.
} 


\section{Incompetencia del inspector de policía para resolver el recurso de apelación en corregimientos donde se haya designado corregidor}

No existe posibilidad jurídica de que, en los corregimientos en los cuales se haya designado corregidor, el inspector de policía pueda asumir función alguna. La legislación vigente se lo prohíbe de la siguiente manera: "En los corregimientos donde se designe corregidor, no habrá inspectores departamentales ni municipales de policía, pues dichos corregidores ejercerán tales funciones" (Ley 136 de 1994, art. 118, inc. 3, Colom.)7. Lo anterior significa que en un corregimiento donde se haya designado corregidor, un inspector de policía no podrá ejercer ninguna de sus funciones; en concreto, está imposibilitado para realizar las acciones relacionadas con la preservación o restablecimiento de la convivencia, pues, por imperio de la ley, el corregidor, en el territorio de su corregimiento, es autoridad de convivencia, además de autoridad administrativa. En relación con la convivencia, solo ha de cumplir con las normas vigentes en la materia, esto es, entre otras, las estipuladas en la Ley 1801 de 2016.

Si por expresa disposición legal los inspectores de policía están impedidos para abordar sus funciones en el territorio de un corregimiento, en el cual se haya designado corregidor, también les está prohibido asumir la competencia para resolver el recurso de apelación que se haya interpuesto contra las medidas correctivas impuestas por miembros uniformados de la

\footnotetext{
7 Esta veda a los inspectores de policía en los corregimientos en los cuales se haya designado corregidor se complementa con otra disposición legal en la cual, expresamente, se manifiesta: "Para el adecuado e inmediato desarrollo de los corregimientos, estos tendrán corregidores como autoridades administrativas [...] Los corregidores, como autoridades de convivencia, cumplirán con las funciones a ellos asignadas, por las normas vigentes en esta materia" (Ley 136 de 1994, art. 118, inc. 1 y 2 , Colom.).
} 
Policía Nacional, que ejerzan sus funciones en ese corregimiento ${ }^{8}$. Así, en los corregimientos en los cuales se haya designado corregidor, todo lo relacionado con asuntos de convivencia, según las atribuciones conferidas por la ley, será de su competencia exclusiva, incluida la facultad de abocar los recursos de apelación.

Pero quizás el argumento jurídico más importante lo establece la propia legislación vigente, pues una de las funciones o facultades del inspector de policía es la resolución del recurso de apelación, contra las medidas previstas en el Artículo 210 de la Ley 1801 de 2016, es decir, aquellas de competencia del personal uniformado de la Policía Nacional, que no ejercen como comandantes de estación, subestación o CAI9. Igualmente, el Código Nacional de Seguridad y Convivencia Ciudadana claramente establece: "La competencia de la autoridad de policía para conocer sobre comportamientos contrarios a la convivencia, se determina por el lugar donde suceden los hechos" (Ley 1801 de 2016, art. 216, Colom.).

En este punto se fija otro factor de competencia, a saber, la línea o límite territorial para el ejercicio de las atribuciones por parte de las autoridades de policía; esta indica que el conocimiento de los comportamientos contrarios a la convivencia únicamente corresponde a las autoridades de policía adscritas o destinadas a prestar sus servicios en determinada área o circunscripción, de conformidad con la división político-administrativa de cada municipio. Esto constituye otro mandato que ofrece plena autonomía

\footnotetext{
${ }^{8}$ Esto se fundamenta en que, según la ley vigente, el corregidor, en el territorio de su corregimiento, es autoridad de convivencia; por consiguiente, si el presunto comportamiento contrario a la convivencia ocurrió dentro del perímetro del corregimiento, entonces, el corregidor es el juez natural para conocer el recurso de apelación contra medidas correctivas impuestas por miembros uniformados de la Policía Nacional.

${ }^{9}$ Esta atribución, por imperio de la ley, también es de competencia de los corregidores, pues estos ejercen las funciones o facultades atribuidas a los inspectores de policía (Ley 136 de 1994, art. 118, inc. 3, Colom.).
} 
a los corregidores, con las limitaciones que establece la ley, en relación con las competencias atribuidas en la Ley 1801 de 2016, las cuales son exactamente las mismas que ostentan los inspectores de policía. Así, teniendo en cuenta las potestades otorgadas en la ley, inspectores de policía y corregidores se encuentran en el mismo nivel o jerarquía funcional, en relación con el conocimiento de comportamientos contrarios a la convivencia.

Asimismo, quien resuelve un recurso de apelación contra una medida correctiva impuesta por un miembro uniformado de la Policía Nacional, naturalmente, también está coadyuvando en la solución de un presunto comportamiento contrario a la convivencia; por consiguiente, si mediante este recurso el corregidor contribuye a esclarecer las circunstancias de tiempo, modo y lugar en la cuales el presunto comportamiento ocurrió, y toma acciones tendientes a aclarar, modificar, revocar o confirmar la decisión, se constituye en parte sustancial para la promulgación del acto administrativo de policía, esto es, es actor o copartícipe en la toma de la decisión. De esta manera, en realidad, el corregidor, o cualquier otra autoridad de policía que aboque un recurso de apelación, está conociendo comportamientos contrarios a la convivencia.

Dicha fundamentación, relacionada con la competencia de los corregidores para conocer el recurso de apelación contra las medidas correctivas impuestas por el personal uniformado de la Policía Nacional adscrito a su corregimiento, se realiza por evidente omisión legislativa. Esta última pudo ocurrir porque en los debates del proyecto de ley sobre este aspecto no se tuvo la astucia de invitar, como asesor, a uno o más corregidores, sino solo a inspectores de policía. Quizás un corregidor sí hubiera advertido la necesidad de complementar el parágrafo $2^{\circ}$ del Artículo 210 de la Ley 1801 de 2016, con las siguientes expresiones: "o un corregidor, 
según el lugar donde sucedieron los hechos". Entonces, la norma habría quedado así: "Contra las medidas previstas en este artículo se concede el recurso de apelación en el efecto devolutivo que resolverá un inspector de policía o un corregidor, según el lugar donde sucedieron los hechos”. Desafortunadamente, no fue así, por ello surge este artículo, que pretende zanjar esta omisión legislativa ${ }^{10}$.

\section{Autoridad competente para resolver el recurso de apelación contra medidas impuestas por comandantes}

En este escrito se ha mostrado porqué los inspectores de policía y corregidores no tienen competencia para adjudicarse la resolución de un recurso de apelación, contra medidas correctivas impuestas por miembros de la Policía Nacional, que se desempeñan como comandantes de estación, subestación o CAI.

Ahora bien, se pretende establecer cuál es la autoridad de policía competente para asumir esta enorme responsabilidad. Para explicarlo es conveniente analizar qué funcionarios ostentan la calidad de autoridad de policía en un municipio y cuál es, en cada caso, el funcionario competente para resolver el recurso de apelación, si a ello hubiere lugar.

Las autoridades de policía, a nivel municipal, son cinco: el alcalde, las autoridades administrativas especiales de policía, los corregidores e inspectores de policía, los miembros uniformados de la Policía Nacional y los comandantes de estación, subestación o CAI (Ley 1801 de 2016, art. 198, núm. 3-6, Colom.).

\footnotetext{
${ }^{10}$ Es conveniente insistir en que al corregidor, en igualdad de condiciones que el inspector de policía, tampoco le está permitido asumir la resolución del recurso de apelación contra las medidas correctivas impuestas por uniformados de la Policía Nacional que laboren en el territorio de su corregimiento, y que, además, ostenten la figura de comandantes de estación, subestación y CAI, pues no existe norma que les otorgue esta atribución.
} 
El alcalde es competente para imponer dos medidas correctivas, proferidas en única instancia (Ley 1801 de 2016, art. 205, núm. 11 y 17, Colom.). Resulta razonable que sean de única instancia, pues, como primera autoridad de policía municipal, ninguna otra entidad administrativa de policía puede modificar, aclarar, revocar o confirmar un acto de policía emitido por este, dado que es la máxima instancia en asuntos relacionados con comportamientos contrarios a la convivencia.

Las autoridades administrativas especiales de policía fueron instituidas solo para resolver el recurso de apelación (Ley 1801 de 2016, art. 207, Colom.); por consiguiente, no toman decisiones en primera instancia, de manera que jamás procederá recurso de apelación contra sus decisiones. Por su parte, los inspectores de policía y corregidores toman algunas de sus decisiones en única instancia (Ley 1801 de 2016, art. 206, núm. 5, lit. a-d, Colom.) y otras se profieren en primera instancia (Ley $1801 \mathrm{de}$ 2016, art. 206, núm. 6, lit. a-i, Colom.); consecuentemente, si existen medidas correctivas impuestas por estos funcionarios que se emiten en primera instancia, pueden ser objeto del recurso de apelación. Este recurso lo debe resolver el alcalde o, como excepción, la autoridad administrativa especial de policía a quien se le haya atribuido, expresamente, esta facultad (Ley 1801 de 2016, art. 205, núm. 8, Colom.).

Los miembros uniformados de la Policía Nacional no cualificados como comandantes pueden imponer medidas correctivas en primera instancia; por consiguiente, contra ellas, procede el recurso de apelación. La autoridad competente para resolverlo es el inspector de policía o el corregidor, según el lugar donde ocurrieron los hechos (Ley 1801 de 2016, art. 210, par. $2^{\circ}$, Colom.; Ley 136 de 1994, art.118, inc. 3, Colom.).

Los miembros uniformados de la Policía Nacional asignados como comandantes de estación, subestación o CAI pueden imponer medidas 
correctivas en primera instancia (Ley 1801 de 2016, art. 209, Colom.). Por consiguiente, contra estas decisiones procede el recurso de apelación, sin embargo, no existe una norma que, expresamente, confiera a determinada autoridad de policía la facultad de resolver el mencionado recurso. Pero el legislador, en el Código Nacional de Seguridad y Convivencia Ciudadana, previó la cláusula general o residual de competencia, asignándola en la máxima autoridad de policía del municipio. Para resolver el recurso de apelación contra medidas correctivas impuestas por comandantes de estación, subestación y CAI, la cláusula general o residual de competencia dicta: "Corresponde al alcalde: [...] 14. Resolver el recurso de apelación de las decisiones tomadas por las autoridades de Policía, en primera instancia, cuando procedan, siempre que no sean de competencia de las autoridades especiales de policía” (Ley 1801 de 2016, art. 205, núm. 14, Colom.).

Debido a que en la Ley 1801 de 2016 no se atribuyó a determinada autoridad de policía, en forma expresa, la facultad para resolver el mencionado recurso, es ineludible e indiscutible que la norma a aplicar, para la resolución de la apelación interpuesta contra los actos de policía proferidos por los comandantes de estación, subestación o CAI, es el Artículo 205, numeral 14 de la Ley 1801. Se trata de una norma que solo es acoplable a los miembros uniformados de la Policía Nacional que fungen como comandantes, pero solo cobija a quienes tienen como misión específica velar por la convivencia de los asociados, es decir, los comandantes de estación, subestación y CAI - de ninguna manera cobija a otra clase de comandantes-.

Para el 3 de enero de 2019, la Policía Nacional contaba con 1240 estaciones, 512 subestaciones y 635 CAI (Policía Nacional, 2019), que reunían en total 2387 unidades operativas de vigilancia y seguridad 
ciudadana, cada una con su correspondiente comandante. De manera que dicha competencia solo aplicaría para estos 2387 comandantes.

Por consiguiente, las únicas autoridades facultadas para abocar el recurso de apelación, impetrado contra las medidas impuestas por los comandantes de estación, subestación o CAI, son los alcaldes y, como excepción, las autoridades administrativas especiales de policía, si a estas, expresamente, se les ha atribuido esta facultad. Para esto se requiere que la competencia se confiera por acuerdo del respectivo concejo municipal (Ley 1801 de 2016, art. 207, en concordancia con los art. 205, núm. 5, 8 y 198, Colom.); mientras no exista esta norma habilitante, la competencia para resolver la apelación contra las medidas correctivas impuestas por los mencionados comandantes será del dominio exclusivo del alcalde ${ }^{11}$. El ejercicio del poder del alcalde como jefe de policía del municipio y, además, como superior funcional natural de los comandantes de estación o subestación, es tan obvio que, aún sin necesidad de interponerse el recurso de apelación por el presunto contraventor o su apoderado, este puede revocar las decisiones de los mencionados comandantes ${ }^{12}$.

\footnotetext{
${ }^{11} \mathrm{El}$ alcalde es la autoridad competente para la resolución del recurso de apelación contra las medidas correctivas impuestas por los comandantes de estación, subestación o CAI, salvo que esta potestad se haya conferido, expresamente, mediante acuerdo municipal, a las autoridades administrativas de policía. Esto es coherente con lo preceptuado en la Constitución Política y en la jurisprudencia de la Corte Constitucional, donde se establece que el superior funcional de los comandantes de estación y subestación, en asuntos relacionados con el derecho de policía, es el alcalde. Así lo ha manifestado la jurisprudencia constitucional:

"[...] el artículo 315,2. de la Ley Fundamental, prescribe que el alcalde es la primera autoridad del municipio y está facultado para ejercer la función de policía local. [...] la medida de cierre de establecimiento abierto al público que puede imponer el comandante de policía [...] puede impugnarse ante el superior jerárquico (el alcalde municipal), lo que garantiza el derecho al debido proceso y el derecho a la defensa" (C.C., Sentencia C-492/02, Colom.).

12 Esta atribución del alcalde tiene como especial condición, además de la ilegalidad del acto de policía, que la revocatoria se realice por motivos de conveniencia pública, según su criterio razonado; así como en procura de la conservación o restablecimiento del orden público, es decir, de la seguridad, tranquilidad, ambiente y salud pública, las cuales, en la legislación actual, conforman las categorías jurídicas de la convivencia.
}

Revista IUSTA

ISSN: 1900-0448 | e-ISSN: 2500-5286 | DOI: https://doi.org/10.15332/25005286

N. 055 | julio-diciembre del 2021 
En resumen, de conformidad con la legislación vigente y la jurisprudencia de la Corte Constitucional, la autoridad competente para resolver el recurso de apelación contra las medidas correctivas impuestas por los miembros uniformados de la Policía Nacional que se desempeñan como comandantes de estación, subestación o CAI, es el alcalde.

Excepcionalmente, esta competencia puede ser ejercida por las autoridades administrativas especiales de policía, siempre y cuando esta atribución, expresa y previamente, se promulgue mediante acuerdo del concejo del respectivo municipio.

\section{Interpretación equivocada del Artículo 222, en relación con el recurso de apelación}

Muchos inspectores de policía y corregidores fundamentan su competencia para resolver el recurso de apelación contra las medidas impuestas por los miembros uniformados de la Policía Nacional, en el parágrafo $1^{\circ}$ del Artículo 222 de la Ley 1801 de 2016. A continuación, se presenta una muestra para ilustrar cómo algunos inspectores de policía esgrimen, como fundamento de su competencia para la resolución del mencionado recurso, la normatividad antes mencionada:

La Inspectora de permanencia Uno, Tercer Turno de Policía Urbana de Primera Categoría del municipio de Medellín, en uso de sus facultades constitucionales y legales, en especial las conferidas por el parágrafo $1^{\circ}$

\footnotetext{
Según la legislación vigente: "Revocación de decisiones de Policía. El alcalde como jefe de policía en el municipio puede revocar las decisiones tomadas por los comandantes de estación o subestación, o quien haga sus veces en relación con las contravenciones y demás decisiones de su competencia, cuando estas sean violatorias de la legalidad o cuando la conveniencia pública lo exija para la conservación y mantenimiento del orden público" (Ley 4 de 1991, art. 12, Colom.).
} 
del artículo 222 de la Ley 1801 de 2016, procede a resolver el recuro de apelación [...]. (Alcaldía de Medellín, Resolución 207/19, 2019)³

De ninguna manera, el parágrafo $1^{\circ}$ del Artículo 222 de la Ley 1801 de 2016, ni el artículo 223 han atribuido competencia alguna para la resolución del recurso de apelación contra los actos de policía emitidos por uniformados de la Policía Nacional. Esgrimir competencia para resolver el recurso de apelación, con fundamento en esta norma, constituye una decisión abiertamente arbitraria, ilegal y temeraria, que podría tener consecuencias jurídicas funestas para el funcionario público que invoque esta norma para tal efecto. Exceptuando los comandantes de estación, subestación o CAI, se insiste que, en relación con el recurso de apelación contra las medidas impuestas por los miembros uniformados de la Policía Nacional, la norma precisa a la que se debe acudir es el parágrafo $2^{\circ}$ del Artículo 210 de la Ley 1801 de 2016, pero jamás el parágrafo $1^{\circ}$ del Artículo 222 de la misma Ley. Además, esta norma se dirige a la resolución del recurso de apelación contra actos de policía impetrados solo contra los servidores públicos descritos en el Artículo 210 de la Ley 1801 de 2016, esta norma no es extensible a otros funcionarios. Igualmente, la

\footnotetext{
13 Otras muestras: "La suscrita Inspectora Décima Urbana de Policía Primera Categoría, en uso de sus atribuciones legales, en especial las conferidas en el artículo 206, 222 de la Ley 1801 de 2016, procede a resolver recurso de apelación interpuesto en contra de medida correctiva aplicada a través de comparendo [...]" (Alcaldía de Manizales, Resolución 2020-9333/20, 2020).

"Procedimiento y Competencia. Según lo establecido en el artículo 222, parágrafo $1^{\circ}$ de la Ley 1801 de 2016, Código Nacional de Policía y Convivencia, el recurso de apelación instaurado en contra de la orden de policía o medida correctiva, será decidido por el inspector de policía correspondiente, y se conocerá mediante el trámite Verbal Inmediato" (Alcaldía de Paipa, sin número de acta o resolución, 12 de agosto de 2020).

"Procede el Despacho a indicar que esta diligencia se lleva a cabo bajo las directrices que estipula el artículo 223 de la Ley 1801 de 2016 [...]. La corregidora de El Hatillo, municipio de Barbosa [...] para decidir respecto de la objeción solicitada por el presunto infractor contra la medida correctiva impuesta [...] por el patrullero [...], la corregidora [...] resuelve: [...] sexto: indicar que contra la decisión proferida proceden los recursos de reposición ante este despacho y, en subsidio, el de apelación ante el superior jerárquico [...]" (Alcaldía de Barbosa, Radicado 047, 2020).
}

Revista IUSTA

ISSN: 1900-0448 | e-ISSN: 2500-5286 | DOI: https://doi.org/10.15332/25005286

N. 055 | julio-diciembre del 2021 
competencia allí establecida no es solo del inspector de policía sino también del corregidor, según el lugar en donde sucedieron los hechos. Por lo tanto, esta competencia puede argüirse de la siguiente manera: 1) para los inspectores de policía, el respaldo jurídico se halla en el parágrafo $2^{0}$ del Artículo 210 de la Ley 1801 de 2016; no hay otra norma en la legislación vigente. b) Para los corregidores, en el mismo artículo, pero, además, debe manifestarse que es en concordancia con lo establecido en la Ley 136 de 1994, Artículo 118.

El parágrafo $1^{\circ}$ de Artículo 222 de la Ley 1801 no se refiere a ninguna atribución de competencias al inspector de policía, solo hace alusión a un trámite o remisión del mencionado recurso. Si con lo expresado en esta norma se pretende una inferencia, deducción o suposición de una atribución de competencias al inspector de policía, además de ir abiertamente en contravía de la jurisprudencia constitucional, de plano sería un pretexto para usurpar las atribuciones expresas, claras y precisas otorgadas a los corregidores y a los alcaldes, sobre la resolución del recurso de apelación contra actos de policía emitidos por otros uniformados de la institución policial, no descritos en el Artículo 210 de la Ley 1801.

La norma establece que el recurso de apelación "se remitirá al inspector de policía". La expresión "remitirá" 14 de ninguna manera otorga competencia expresa al inspector de policía para erigirse como superior funcional de todos los uniformados, arrebatando competencias expresas conferidas a otras autoridades de policía, como el corregidor y el alcalde; a estos

\footnotetext{
14 No se puede tener tanta laxitud o distensión en la interpretación de la norma en la cual se establece la remisión del recurso de apelación, previamente citada; el verbo rector de esta norma es remitir, el cual significa "enviar, mandar, trasladar, llevar, remesar o tramitar" (Word Reference, 2021), pero con ello no se otorga ninguna facultad, poder o potestad a nadie.
} 
funcionarios, como se ha argumentado en este artículo, en otras normas legales se les ha conferido expresamente la competencia para dirimir el recurso de apelación. En concreto, los corregidores tienen competencia para abocar este recurso, considerando que el lugar donde el uniformado presta sus servicios es un corregimiento en el cual se ha designado corregidor; igualmente, los alcaldes y los uniformados que ostenten la calidad de comandantes tienen esta facultad (Ley 1801 de 2016, art. 222, Colom.).

En este sentido, las competencias para la resolución del recurso de apelación contra los actos de policía emitidos por los miembros uniformados de la Policía Nacional se distribuyen entre el alcalde, el corregidor y el inspector de policía. Para definir cuál de los tres es competente se deben analizar dos factores: 1) el lugar de ocurrencia de los hechos, para establecer si es competencia del inspector de policía o del corregidor; y 2) el cargo de comandante de estación, subestación o CAI, para determinar si la competencia es del alcalde o de la autoridad administrativa especial de policía, siempre y cuando, por acuerdo del concejo de cada municipio, como titular del poder residual de policía, se haya conferido esta atribución.

Por ende, si el inspector de policía recibe un recurso de apelación, y se percata de su falta de competencia para resolverlo, su deber es, a su vez, remitirlo al funcionario competente - este es el deber ser-. La deontología del derecho indica que tramitar la actuación al funcionario con la potestad expresa para resolver el recurso mencionado es obligatorio, adecuado y pertinente. Llevar a cabo otra actuación riñe con sus reales y expresas atribuciones, dado que: "Los servidores públicos solo pueden realizar los actos previstos por la Constitución, las leyes o los reglamentos, y no 
pueden, bajo ningún pretexto, improvisar funciones ajenas a su competencia” (C.C., Sentencia C-337/93, Colom.).

De todas maneras, la expresión previamente citada, empleada por el legislador en la norma respecto a la remisión, es desafortunada y nefasta, pues dispone que todo recurso que se interponga contra actos de policía emitidos por uniformados de la Policía Nacional se canalice o encause a través del inspector de policía, sea o no de su competencia, lo que constituye un absurdo. Además del desgaste ocasionado por la tramitología, esta decisión viola principios fundamentales del debido proceso de policía, tales como: la inmediatez, la celeridad y la oportunidad. Con esta norma, a los inspectores de policía se les ha de remitir todos los recursos de apelación que se interpongan contra las medidas correctivas impuestas por todos los uniformados de la Policía Nacional; luego, el inspector seleccionará los que son de su competencia y los que no, posteriormente, abordará los primeros y hará otra remisión de los segundos al corregidor, al alcalde o a la autoridad especial de policía, según la competencia que, a cada uno de ellos, corresponda. iComo si los inspectores de policía no tuvieran nada que hacer!

La redacción de la norma pudo ser mejor, es evidente la ausencia de técnica legislativa, considerada como "el arte y la destreza necesarias para llegar a una correcta y eficaz elaboración de la ley" (Castells, 1997). La composición escritural, en este punto del trámite del recurso de apelación, podría haber sido: "se remitirá al inspector de policía, corregidor, alcalde o autoridad especial de policía, según su competencia”. Entonces, el parágrafo $1^{\circ}$ del Artículo 222 de la Ley 1801 de 2016 habría quedado así: "En contra de la orden de Policía o la medida correctiva, procederá el recurso de apelación, el cual se concederá en el efecto devolutivo y se remitirá al inspector de policía, corregidor, alcalde o autoridad especial de 
policía, según su competencia, dentro de las veinticuatro (24) horas siguientes. El recurso de apelación se resolverá dentro de los tres (3) días hábiles siguientes al recibo de la actuación, y será notificado por el medio más eficaz y expedito". Por infortunio, la norma se plasmó de otra manera y por eso ha dado origen a disímiles interpretaciones, entre otras, la de pretender usurpar funciones que, taxativamente, corresponden, por imperio de la ley, a otras autoridades de policía.

\section{Riesgo del inspector de policía o del corregidor, en resolución del recurso de apelación, ante impedimento o recusación}

Toda potestad trae consigo responsabilidades y, a veces, ligeros o graves inconvenientes; por eso, en este aparte, se pretende predecir algunos inconvenientes que pueden presentarse al resolver el recurso de apelación, especialmente, por parte de inspectores de policía, pero también para los corregidores. Cuando el inspector de policía o el corregidor asumen la resolución de un recurso de apelación que, expresa y diáfanamente, es de su competencia, automáticamente quedarán impedidos o pueden ser recusados, en el evento que el presunto comportamiento contrario a la convivencia, con posterioridad a la resolución del mencionado recurso, amerite el adelantamiento del proceso verbal abreviado, para imponer o no medida correctiva de su competencia ${ }^{15}$.

\footnotetext{
${ }^{15}$ Así lo establece la legislación vigente: "Las autoridades de policía podrán declararse impedidas o ser recusadas por las causales establecidas en las disposiciones del Código de Procedimiento Administrativo y de lo Contencioso Administrativo" (Ley 1801 de 2016, art. 229, Colom.). Una de estas causales constitutivas de impedimento o recusación radica en haber conocido el asunto con anterioridad, como dispone la ley: "todo servidor público que deba adelantar o sustanciar actuaciones administrativas, realizar investigaciones, practicar pruebas o pronunciar decisiones definitivas, podrá ser recusado si no manifiesta su impedimento, por: [...] Haber conocido del asunto, en oportunidad anterior" (Ley 1437 de 2011, art. 11, núm. 2, Colom.). Por otro lado, la legislación disciplinaria establece: "Son faltas gravísimas las siguientes: [...] No declarase impedido oportunamente, cuando exista obligación de hacerlo, demorar el
} 
La congestión en estos despachos se incrementará y, tal vez, colapsará en la medida en que los abogados litigantes comiencen a recusar ante los inspectores de policía y corregidores por la existencia de un medio de prueba objetivo, público y escrito o grabado, en el que nítidamente se establece que el funcionario de policía anteriormente conoció del asunto, en forma pormenorizada.

Haber otorgado competencia a inspectores de policía y a corregidores para la resolución de recursos de apelación en asuntos en los cuales, casi siempre, posteriormente deben adelantar pruebas o tomar decisiones definitivas, constituye un desacierto legislativo. En el momento, aun sin que los inspectores o corregidores hayan sido recusados a fondo, se observa la congestión y una situación estresante en sus despachos, que se incrementará, pues los abogados litigantes se enterarán de esta perspectiva - además de la obligación de los funcionarios mencionados de declarase impedidos-.

Igualmente, el haber establecido el recurso de apelación contra las medidas correctivas, como la amonestación (llamado de atención), participación en programa comunitario o actividad pedagógica de convivencia (asistencia a un lugar con propósitos didácticos, educativos o formativos) o remoción de bienes (retiro y ubicación en otro lugar, de elementos que obstruyen el espacio público), constituye otro exabrupto jurídico, que solo congestiona el flujo de trabajo de los inspectores de policía y de los corregidores. En estas tres medidas no es razonable el recurso de apelación, pues son de carácter educativo, de manera que solo

trámite de las recusaciones, o actuar después de separado del asunto" (Ley 734 de 2002, art. 48, núm. 46, Colom.). Asimismo, la nueva legislación disciplinaria tipifica como falta gravísima: "[...] no declarase impedido oportunamente, cuando exista obligación de hacerlo, demorar el trámite de las recusaciones, o actuar después de separado del asunto" (Ley 1952 de 2019, art. 56, núm. 5, Colom.). 
buscan crear conciencia o cultura ciudadana y, quizá, ni siquiera afectan en grado mínimo algún derecho.

Por ende, si los uniformados de la Policía Nacional están facultados para imponer las medidas correctivas de amonestación y participación en actividad pedagógica en todos los comportamientos contrarios a la convivencia, estas son apeladas, y el inspector de policía o el corregidor resuelven esas impugnaciones. Por imperio de la ley, estos funcionarios quedan, en el acto, imposibilitados para adelantar el proceso verbal abreviado en asuntos de su competencia. Por eso es un error garrafal haber otorgado a los funcionarios antes mencionados la responsabilidad de resolver dichos recursos de apelación.

\section{Riesgos por abocar la resolución de la apelación, sin competencia expresa para hacerlo}

A continuación, enfatizamos en las posibles consecuencias de orden jurídico que surgen al asumir la competencia para la resolución del recurso de apelación cuando no existe una norma jurídica que, expresamente, otorgue esta atribución, por ello es conveniente insistir en que:

En el Estado de derecho, el individuo puede hacer todo aquello que no le esté expresamente prohibido por la ley. En cambio, la autoridad actúa siempre con competencias que en principio son limitadas. [...] [P]ara que la autoridad pueda actuar, necesita mostrar la norma que la faculte para ello; si no existe esa norma, le está prohibida esa actuación. Las competencias de la autoridad son siempre expresas y explícitas; no existen competencias implícitas, ni por analogía [...]. (C.C., Auto 059/o9, Colom.)

A lo anterior se agrega que no se pueden asumir competencias basadas en deducciones, convicciones personales, inferencias o remisiones, dispuestas o no en la norma jurídica. Sobre competencias asumidas con fundamento 
en inferencias, inducciones, deducciones o suposiciones, recientemente se han tomado determinaciones relacionadas, como las que se exponen a continuación.

En primer lugar, teniendo como referencia el caso expuesto en páginas anteriores, relacionado con no portar la cédula de ciudadanía, en donde mediante sentencia T-385 de 2019 se realizó un análisis de legalidad de la orden de comparendo impuesta por una conducta que no se encuentra tipificada por la Ley 1801 de 2016.

En segundo lugar, tenemos los hechos presentados el 11 de febrero de 2019, donde un uniformado de la Policía Nacional en Bogotá impuso un comparendo a un ciudadano que compró una empanada en la vía pública, señalando multa tipo 4, bajo la inferencia de que se había cometido un comportamiento contrario a la convivencia consistente en "promover o facilitar el uso u ocupación del espacio público en violación de las normas y jurisprudencia constitucional vigente" (Ley 1801 de 2016, art. 140, núm. 6, Colom.). Esta actuación policial fue objeto de críticas, burlas y sarcasmos, en programas de humor transmitidos por diferentes medios de comunicación nacionales e internacionales.

El presunto infractor pagó el 50 \% de la supuesta multa, por haberlo hecho dentro de los cinco días siguientes a la imposición del comparendo, lo que significaría una aceptación tácita de su responsabilidad. No obstante, como el hecho fue de amplio conocimiento público, por solicitud de la Personería de Bogotá, la Inspectora de Atención Prioritaria 17 Distrital de Policía, en audiencia celebrada el 8 de marzo de 2019, decidió no declarar responsable al presunto infractor y, por consiguiente, dispuso la devolución del dinero pagado (Inspección de Atención Prioritaria Distrital 17 de Policía, Radicado 20196210014792/19, 2019). Por fortuna, para el uniformado que impuso el comparendo, el asunto no conllevó la instancia 
de tutela, por lo tanto, no se compulsaron copias para que esta actuación fuera investigada disciplinaria y penalmente ${ }^{16}$.

Las actuaciones policiales mencionadas permiten prever el riesgo para el inspector de policía o el corregidor que profiera resolución sobre una apelación interpuesta contra un acto de policía emitido por un miembro uniformado de la Policía Nacional, que se desempeñe como comandante de estación, subestación o CAI.

Por consiguiente, como se ha defendido en este artículo, la norma a aplicar no es el Artículo 222, pues este no confiere competencia a nadie, sino que simplemente dispone que todo recurso de apelación contra decisiones de fondo proferidas por funcionarios uniformados debe remitirse al inspector de policía, quien abocará los que son de su competencia y, a su vez, remitirá los que no son a los respectivos funcionarios competentes. En este sentido, si el inspector de policía o el corregidor resuelven un recurso de apelación contra un miembro uniformado de la Policía Nacional, que ostente el cargo de comandante de estación, subestación o CAI, estarían incursos en presunto delito de abuso de la función pública ${ }^{17}$, pues "el eje de la conducta del delito de abuso de la función pública se refiere a una ilegalidad signada por desbordar una atribución funcional que le corresponde ejecutar a otro funcionario, la cual consiste en la ilegalidad del acto" (C.S.J., Sentencia 51778/18, Colom.).

\footnotetext{
16 La Corte Constitucional declaró como exequibles las expresiones "promover" y "facilitar" contenidas en la norma, en el entendido de que no comprenden conductas como adquirir o consumir bienes o servicios ofrecidos por vendedores informales en el espacio público (C.C., Sentencia C-489/19, Colom.).

17 "El servidor público que abusando de su cargo realice funciones diversas de las que legalmente le correspondan, incurrirá en prisión de dieciséis (16) a treinta y seis (36) meses e inhabilitación para el ejercicio de derechos y funciones públicas por ochenta (80) meses" (Ley 599 de 2000, art. 428, Colom.).
} 
En síntesis, si el inspector de policía o el corregidor resuelven un recurso de apelación contra un miembro uniformado de la Policía Nacional que ostente el cargo de comandante de estación, subestación o CAI, podrían ser objeto de investigaciones penales y disciplinarias ${ }^{18}$, que eventualmente ocasionarían privación de su libertad y/o destitución (Rumbo, 2020).

\section{Conclusiones}

Las competencias atribuidas a los servidores públicos se rigen por el principio universal del derecho, denominado principio de legalidad, el cual establece que las autoridades solo podrán hacer lo que esté estricta, expresa, clara y previamente definido en el ordenamiento jurídico; de lo contrario, al servidor público le está vedado arrogarse competencias basadas en supuestos, inferencias, deducciones u otros pretextos.

En la jurisprudencia del Consejo de Estado se advierte que la falta de competencia es causal, por sí sola, de la ilegalidad del acto; asimismo, considera y alerta que una de las maneras de violar el principio de legalidad es asumir competencias que expresamente no han sido otorgadas por la ley; además, hace referencia a la usurpación de competencias, cuando un servidor público se arroga facultades que, por ley, han sido conferidas a otro funcionario de mayor o menor jerarquía.

\footnotetext{
18 Los funcionarios estarían incursos en presuntas faltas disciplinarias gravísimas contempladas en el Código Único Disciplinario, Ley 734 de 2002, vigente hasta el 30 de junio de 2021: "realizar objetivamente una descripción típica consagrada en la ley como delito sancionable a título de dolo, cuando se cometa en razón, con ocasión o como consecuencia de la función o cargo, o abusando del mismo" (Ley 734 de 2002, art. 48, núm. 1, Colom.). Asimismo, la nueva legislación disciplinaria lo establece como falta gravísima: "Faltas que coinciden con descripciones típicas de la ley penal. Cuando la conducta no pueda adecuarse a ninguna de las anteriores faltas, en virtud de los principios de especialidad y subsidiariedad, constituirá falta gravísima realizar objetivamente una descripción típica consagrada en la ley como delito sancionable a título de dolo, cuando se cometa en razón, con ocasión o como consecuencia de la función o cargo, o abusando de él" (Ley 1952 de 2019, art. 65, Colom.).
} 
Por imperio de la ley vigente, para efectos de emisión de actos administrativos de policía, los miembros uniformados de la Policía Nacional han sido divididos en dos grupos bien definidos: por un lado, el personal uniformado, que funge como comandantes de estación, subestación o CAI y, por otro, el resto de uniformados que no ostentan estos cargos.

La autoridad competente para resolver el recurso de apelación contra actos de policía emitidos por miembros uniformados de la Policía Nacional es el inspector de policía. El respaldo jurídico correspondiente se encuentra en el parágrafo $2^{\circ}$ del Artículo 210 de la Ley 1801 de 2016. Sin embargo, hay dos excepciones en las cuales el inspector de policía no está habilitado para este efecto, así: 1) si el lugar de ocurrencia de los hechos es en un corregimiento en el cual se ha designado corregidor; y 2) si el miembro uniformado ha sido designado como comandante de estación, subestación o CAI.

De ninguna manera, el parágrafo $1^{\circ}$ del Artículo 222 de la Ley 1801 de 2016 atribuye competencia alguna al respecto. Por lo tanto, esgrimir esta norma como fundamento de competencia constituye una decisión abiertamente arbitraria, ilegal y temeraria, que podría tener consecuencias jurídicas funestas para el funcionario público que la invoque para tal efecto. El parágrafo $1^{0}$, antes mencionado, solo hace alusión a un trámite 0 remisión del mencionado recurso al inspector de policía, quien lo abocará si es de su competencia; de lo contrario, lo remitirá, a su vez, al funcionario competente para resolverlo.

El corregidor es el funcionario competente para resolver el recurso de apelación contra actos de policía emitidos por miembros uniformados de la Policía Nacional, destinados a un corregimiento en el cual se ha designado corregidor. El fundamento jurídico radica en el parágrafo $2^{\circ}$ del 
Artículo 210 de la Ley 1801 de 2016, en concordancia con el Artículo 118 de la Ley 136 de 1994. No obstante, no está habilitado para hacerlo, si la apelación es contra una medida impuesta por un miembro uniformado designado como comandante de estación, subestación o CAI.

El servidor público competente para resolver el recurso de apelación contra las medidas correctivas impuestas por los miembros uniformados de la Policía Nacional que se desempeñan como comandantes de estación, subestación o CAI, es el alcalde. Excepcionalmente, esta competencia solo pueden ejercerla las autoridades administrativas especiales de policía, siempre y cuando esta atribución, expresa y previamente, se promulgue mediante acuerdo del concejo del respectivo municipio; mientras no exista esta norma habilitante, la competencia para resolver la apelación contra las medidas correctivas impuestas por los mencionados comandantes será exclusiva del alcalde. El fundamento jurídico radica en el numeral 14 del Artículo 205 de la Ley 1801 de 2016, en concordancia con los artículos 198, numeral 5 y 207, inciso 2.

El inspector de policía o el corregidor automáticamente quedarían impedidos o podrían ser recusados en el evento que asuman la resolución de un recurso de apelación que, expresa y diáfanamente, no es de su competencia, si con posterioridad a la resolución del mencionado recurso correspondiera adelantar, por el mismo comportamiento, proceso verbal abreviado para imponer o no, medida correctiva de su competencia. En estas circunstancias, si no se declara el impedimento, tanto el inspector de policía como el corregidor estarían incursos en una presunta falta disciplinaria gravísima, que podría desembocar en destitución e inhabilidad para el ejercicio de funciones públicas.

Por último, si el inspector de policía o el corregidor resuelven recursos de apelación interpuestos contra medidas impuestas por miembros 
uniformados de la Policía Nacional, que ostenten el cargo de comandante de estación, subestación o CAI, estarían incursos en el presunto delito de abuso de la función pública, considerando que esta acción coincidiría con la descripción típica de la ley penal del presunto delito antes mencionado.

\section{Referencias}

Alcaldía de Barbosa, Secretaría de Gobierno y Convivencia Ciudadana y Corregiduría de El Hatillo. (2020). Radicado 047 del 13 de octubre de 2020. Acta de Audiencia Pública para decidir respecto de la objeción solicitada por el presunto infractor contra la medida correctiva impuesta.

Alcaldía de Manizales. Resolución 2020-9333 A. Por la cual se resuelve un recurso de apelación sobre la imposición de una medida correctiva en aplicación del proceso verbal inmediato. Junio 2 de 2020. Inspección Décima Urbana de Policía Primera Categoría.

Alcaldía de Medellín. Resolución 207 de 2019. Por la cual se resuelve un recurso de apelación. Diciembre 31 de 2019. Inspección de Permanencia Uno.

Alcaldía de Paipa. Sin número de Acta o Resolución. Por medio de la cual se resuelve el recurso de apelación interpuesto contra la orden de comparendo o medida correctiva n. ${ }^{\circ}$ 15-516-1799. Agosto 12 de 2020. Inspección Rural de Policía Pantano de Vargas.

Alcaldía Mayor de Bogotá, Secretaría de Gobierno e Inspección de Atención Prioritaria Distrital 17 de Policía. (2019). Radicado 20196210014792, Comparendo 11001437412, marzo 8 de 2019.

Borbón Torres, J. A. (2019). La política de defensa y seguridad democrática en el Estado social de derecho. Revista IUSTA, 5O(1), 97-120. https://doi.org/10.15332/1900$\underline{0448.2019 .0050 .04}$

Castells, A. (1997, 7 de noviembre). Estudios de técnica legislativa: panorama. Conferencia dictada en el marco del Seminario Nacional de Técnica Legislativa organizado por el Instituto de Capacitación Parlamentaria de la Honorable Cámara de Diputados de la Nación y la Secretaría de Extensión Universitaria y Bienestar Estudiantil de la Universidad de Buenos Aires, Buenos Aires, Argentina. 
Mendieta Pineda, L. M., Goyte Pierre, M. y Oviedo I. Y. (2020). El juez de ejecución de penas y las medidas de seguridad en Colombia: un análisis crítico sobre sus orígenes, consagración normativa y funciones. Via Inveniendi et Iudicandi, 15(1), 91-118.

Colombia. Ley 4 de 1991. Por la cual se dictan normas obre orden público interno, policía cívica local y se dictan otras disposiciones. Enero 16 de 1991. D.O. núm. 39.631.

Colombia. Ley 136 de 1994. Por la cual se dictan normas tendientes a modernizar la organización y el funcionamiento de los municipios. Junio 2 de 1994. D.O. núm. 41.377 .

Colombia. Ley 599 de 2000. Por la cual se expide el Código Penal. Julio 24 de 2000. D.O. núm. 44.097.

Colombia. Ley 734 de 2002. Por la cual se expide el Código Disciplinario Único. Febrero 5 de 2002. D.O. núm. $44 \cdot 708$.

Colombia. Ley 1437 de 2011. Por la cual se expide el Código de Procedimiento Administrativo y de lo Contencioso Administrativo. Enero 18 de 2011. D.O. núm. 47.956 .

Colombia. Acto Legislativo 01. Por medio del cual se adopta una reforma de equilibrio de poderes y reajuste institucional y se dictan otras disposiciones. Julio 1 de 2015.

Colombia. Ley 1801 de 2016. Por la cual se expide el Código Nacional de Seguridad y Convivencia Ciudadana. Julio 29 de 2016. D.O. núm. 49.949.

Colombia. Ley 1952 de 2019. Por la cual se expide el Código General Disciplinario, se deroga la Ley 734 de 2002, y algunas disposiciones de la Ley 1474 de 2011, relacionadas con el derecho disciplinario. Enero 28 de 2019. D.O. núm. 50.850.

Consejo de Estado [C.E.], Sección Tercera, septiembre 19, 2016, C.P.: J. O. Santofimio Gamboa, Expediente 47693, [Colom.].

Constitución Política de Colombia [C.P.] (1991). (Colom.).

Corte Constitucional de Colombia [C.C.], agosto 19, 1993, M.P.: V. Naranjo Mesa, Sentencia C-337/93, [Colom.].

Corte Constitucional de Colombia [C.C.], junio 21, 2000, M.P.: A. Beltrán Sierra, Sentencia C-725/oo, [Colom.]. 
Corte Constitucional de Colombia [C.C.], junio 26, 2002, M.P.: J. Córdoba Triviño, Sentencia C-492, [Colom.].

Corte Constitucional de Colombia [C.C.], mayo 3, 2007, M.P.: J. Araújo Rentería, Sentencia C-319/07, [Colom.].

Corte Constitucional de Colombia [C.C.], enero 30, 2008, M.P.: C. I. Vargas Hernández, Auto 016.

Corte Constitucional de Colombia [C.C.], febrero 10, 2009, M.P.: M. G. Monroy Cabra, Auto 059, [Colom.].

Corte Constitucional de Colombia [C.C.], agosto 21, 2019, M.P.: J. F. Reyes Cuartas, Sentencia T-385/19, [Colom.].

Corte Constitucional de Colombia [C.C.], septiembre 17, 2019, M.P.: G. S. Ortiz Delgado, Sentencia C-428/19, [Colom.].

Corte Constitucional de Colombia [C.C.], octubre 22, 2019, M.P.: A. Rojas Ríos, Sentencia C-489/19, [Colom.].

Corte Suprema de Justicia [C.S.J.]. Sala de Casación Penal, octubre 31, 2018, M.P.: J. L. Barceló, Sentencia 51778, [Colom.].

Ministerio de Defensa Nacional. (2017). Por medio del cual se adiciona el Título 8 a la Parte 2 del libro 2 del Decreto 1070 de 2015, "Decreto Único Reglamentario del Sector Administrativo de Defensa”, para reglamentar, parcialmente, el Código Nacional de Policía y Convivencia. [Decreto 1284 de 2017].

Policía Nacional de Colombia. (2019). Informe de gestión 2018 [presentación de diapositivas]. Https://oas.policia.gov.co

Rumbo Bonfil, C. (2020). La construcción de los derechos sociales desde la privación legal de la libertad en América Latina. Via Inveniendi et Iudicandi, 15(2), 165-186. https://doi.org/10.15332/19090528/6246

Torregrosa Jiménez, R. y Villalba García, N. A. (2020). Adecuación de la acción de lesividad a los medios de control contemplados en la Ley 1437 del 2011. Via Inveniendi et Iudicandi, 15(2), 297-319. https://doi.org/10.15332/19090528/6252

Revista IUSTA

ISSN: 1900-0448 | e-ISSN: 2500-5286 | DOI: https://doi.org/10.15332/25005286

N. ${ }^{0} 55$ | julio-diciembre del 2021 
Vargas Florián, S. M. (2018). La fuerza vinculante de la jurisprudencia del Consejo de

Estado. IUSTA, 1(48), 119-144. https://doi.org/10.15332/s1900-

0448.2018.0048.05

Word Reference. (2021). Remitir (sinónimos). En Diccionario de sinónimos y antónimos. https://www.wordreference.com/sinonimos/remitir 